\title{
Study on the Improvement of Fresh Electricity Suppliers Cold Chain Logistics Service Quality
}

\author{
Yanhong Liu \\ Beijing Wuzi University, Beijing, China \\ Email:1329273987@qq.com
}

How to cite this paper: Liu, Y.H. (2016) Study on the Improvement of Fresh Electricity Suppliers Cold Chain Logistics Service Quality. Journal of Service Science and Management, 9, 477-484.

http://dx.doi.org/10.4236/jssm.2016.96050

Received: October 11, 2016

Accepted: November 29, 2016

Published: December 2, 2016

Copyright $\odot 2016$ by author and Scientific Research Publishing Inc. This work is licensed under the Creative Commons Attribution International License (CC BY 4.0).

http://creativecommons.org/licenses/by/4.0/

\begin{abstract}
Improvement of service quality in cold chain logistics of fresh electricity suppliers has great significance to reduce logistics costs, get access to vast number of customer groups and enhance core competitiveness. This paper uses SIPOC (Suppliers, Input, Process, Output, Customers) model to draw the fresh electricity suppliers cold chain logistics service flow chart, by using the fishbone diagram to analyze the influential factors based on the mastery of fresh electricity suppliers cold chain logistics service flow. Finally, this paper puts forward 6 measures to improve the fresh electricity suppliers cold chain logistics service quality: to strengthen staff training and improve service awareness; to improve logistics equipment and develop cold chain technology; to improve the material supply and meet customer demand; to optimize the distribution route and develop the intelligent logistics; to carry out lean management and reduce logistics cost; to make cold chain logistics service quality management system and strengthen quality control and supervision.
\end{abstract}

\section{Keywords}

Cold Chain Logistics, Service Quality, SIPOC Model, Fishbone Diagram

\section{Introduction}

In the environment of growing development of fresh electricity suppliers various problems concerning fresh products cold chain logistics become obvious, which would bring threats to the quality of cold chain logistics service. Today, people's awareness of food safety is increasing, and online shopping logistics service quality requirements are also getting higher and higher. Under the background of supply side reform, the improvement of fresh electricity suppliers cold chain logistics service plays an important role in promoting the development of electronic commerce in fresh field, cold chain logistics and online consumption. 
Many scholars have made studies on the cold chain logistics service quality. First, the theory of quality management has been applied to the management of cold chain logistics service quality. Xiaoxin Shi et al. applied the Six Sigma management to the improvement of cold chain logistics in our country and believed that the application of Six Sigma DMAIC (Define/Measure/Analyze/Improve/Control) process improvement model can continuously improve the quality of vegetable cold chain logistics process [1]. Xu He discussed agricultural products cold chain logistics quality based on the HACCP (Hazard Analysis and Critical Control Point), and analyzed the harm and the key control points of agricultural products cold chain logistics according to the principle of quality control system [2]. Second, some scholars have carried on the cold chain logistics service quality evaluation index system theory and application researches. Hongli Chen established a cold chain logistics service quality evaluation model based on FAHP, it provides a practical theoretical guidance and model reference to improve the quality of fresh food cold chain logistics service [3]. Jieling Hou carried out researches in electronic commerce of fresh agricultural products cold chain logistics service quality, established the evaluation index system, and provided a reference for the research of logistics service quality evaluation for electronic commerce subdivision products in the future [4].

This article draws fresh electricity suppliers cold chain logistics service improvement flow chart based on the SIPOC model, then analyses the key influential factors of fresh electricity suppliers cold chain logistics service process by using the fishbone diagram. On these bases, it puts forward a series of measures to continually improve the quality of fresh cold chain logistics service, which is conducive to improving the cold chain logistics service quality and customer satisfaction and thus stimulating consumption.

\section{Fresh Electricity Suppliers Cold Chain Logistics Service Process}

SIPOC model is the organization system model which is put forward by Deming. It is a common technology used for process management and improvement, the model includes five parts: 1) Suppliers: an organization that provides key information, materials, or other resources to the core process. 2) Input: resources provided by suppliers. 3) Process: activities that add value to the input. 4) Output: the results of core process. 5) Customers: the person or organization that accepts the output, including internal and external customers.

The improvement of fresh electricity suppliers cold chain logistics service quality is for the improvement of the whole process so as to meet the needs of consumers and improve customer satisfaction. The process begins with accepting an order, and ends with customer receiving fresh products. As shown in Figure 1, fresh electricity suppliers cold chain logistics service process begins with accepting orders, after which fresh electricity supplier would provide fresh products, then electric business enterprise self-run logistics or the third party logistics would check fresh products in the supply place, then they would package, load and transport the fresh products by cold chain technology, and carries on the real time information tracking to the entire transportation 


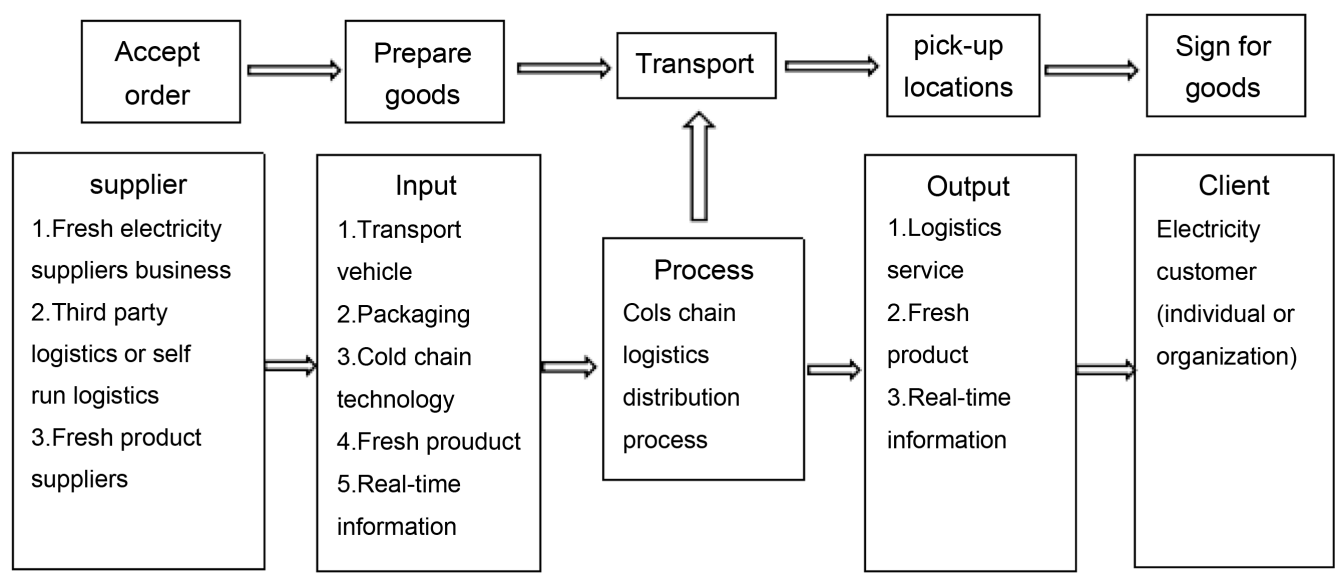

Figure 1. Fresh electricity suppliers cold chain logistics service SIPOC map.

process. By drawing the SIPOC map of fresh cold chain logistics service to clearly show fresh electricity suppliers cold chain logistics process, it is helpful to identify the key risk points in the process, and to provide help for the quality improvement of the process [5].

\section{Analysis of Factors Affecting the Fresh Electricity Supplier Cold Chain Logistics Service Quality}

The fishbone diagram is an analysis method to discover "The root cause" of problems. This article analyses the key influential factors of fresh electricity suppliers cold chain logistics service process by using the fishbone diagram. Aiming at the problem of the low service quality level of fresh electricity suppliers cold chain logistics, the causes of which can be summarized as the following six types: personnel, machine, material, method, environment and measurement, Through, the causal analysis to seek out the causes for such types, it can be argued that the main factors affecting the fresh electricity suppliers cold chain logistics service quality root in: 1) the order picking personnel, handling personnel and logistics delivery personnel; 2) transport vehicles, handling equipment and cold chain equipment; 3) packaging materials and fresh products; 4) distribution route selection, construction of pick-up locations and logistics information tracking; 5) natural environment and logistics operation environment; 6) standard operating procedures, product failure rate and efficiency of logistics. The six kinds of causes and related factors have been made according to the fish distribution situation to form a fishbone analysis diagram of fresh electricity suppliers cold chain logistics service quality, as shown in Figure 2.

\subsection{Personnel}

The main factors which affect the fresh electricity suppliers cold chain logistics service quality come from the order picking personnel, handling, loading and unloading personnel and logistics delivery personnel. The low staff service consciousness, inadequate training, physical fatigue, low image and quality of direct distribution personnel, etc., 


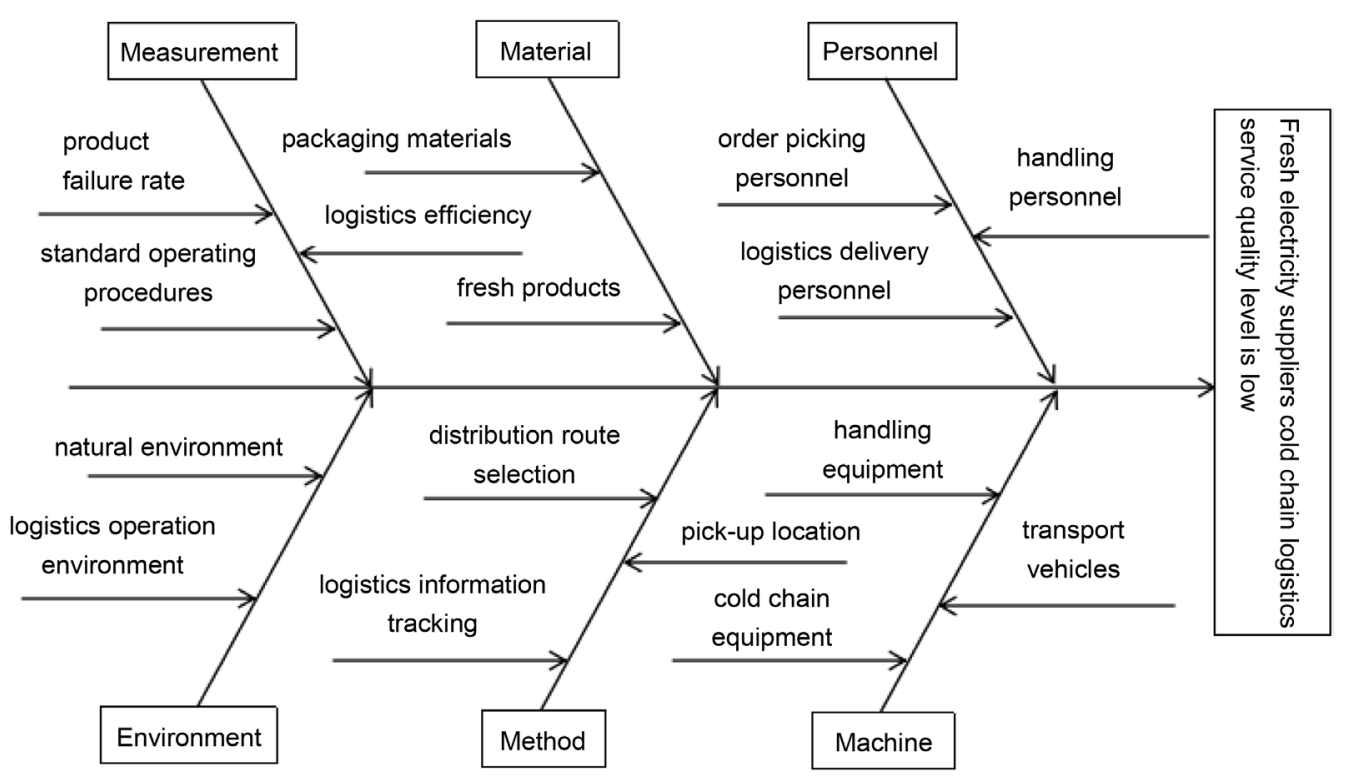

Figure 2. Fishbone analysis diagram of fresh electricity suppliers cold chain logistics service quality.

all these factors can cause damage to product freshness, simply because of the unpunctual arrival of order and also cause subsequent decline of consumer satisfaction.

\subsection{Machine}

Transport vehicles are important carriers of fresh products distribution. Scheduling problem of vehicle on the part of self-operated logistics or the third party logistics will cost more time for loading and thus affect the distribution schedule. The flexibility and automation of machine handling, loading and unloading can improve the efficiency of product movement. And good equipment quality can reduce the maintenance cost and the product damage risk alongside improving logistics efficiency, so as to reduce the total logistics cost. In addition, the distribution vehicles and distribution personnel that be used in "Last Mile" are the last part of logistics service and they represent the business enterprise image, influence consumers' sense which in turn affects customer satisfaction of online shopping. What's more, for fresh products, to maintain its freshness is the most important of the cold chain logistics service. Therefore it can be concluded that cold chain equipment applications play a crucial role, which holds the key factor to affect the freshness of fresh product [6].

\subsection{Material}

As for packaging materials of fresh product, the appropriate fresh keeping materials should be employed according to the characteristics of different fresh products, the purpose of which is to ensure product freshness. What is more, different packaging technology should be taken due to different customer requirements. Mutual honesty and trust mechanism would be built if fresh products can be packaged for the freshness. Therefore, packaging materials and fresh products are also important factors that would affect the quality of fresh electricity suppliers cold chain logistics service. 


\subsection{Method}

The methodological factors of fresh electricity suppliers cold chain logistics services mainly include: reasonable logistics distribution route; unsatisfactory spatial arrangement of pick-up locations; delayed logistics information. The unreasonable logistics distribution route would have direct impact on distribution schedule. The layout of pick-up locations would directly affect consumer satisfaction. Electricity suppliers and logistics enterprises have cooperated in the construction of a variety of convenient pick-up locations, such as, elf-taking cabinets or locations in communities and campuses, etc. However, the pick-up locations are not perfect layout in two or three lines of urban and rural areas. The timely tracking of logistics information is also one of the factors that affect the online shopping experience of consumers. To improve the real time tracking system not only provide customers with value-added services but also information about logistics service schedule so as to carry out the next logistics plan in time [7].

\subsection{Environment}

There exist two environmental factors concerning fresh electricity suppliers cold chain logistics service process. One is the natural environment, the changes of which may lead damage to fresh products, traffic interruption and other risks that would influence the freshness of products and the according arrival time. The other is the logistics operation environment, including the warehouse environment of fresh supplier, distribution site environment, and the interior environment of fresh product transport vehicle. The logistics environment can cause various kinds of waste during the course of logistics operation, increase logistics cost which is one of the indexes to evaluate logistics service quality. Therefore, it is possible that the increase of logistics cost brought by environmental factors would be ignored, due to which customer satisfaction would be on the decline. In such cases, lean logistics management is a good way to eliminate the waste brought about in logistics operations.

\subsection{Measurement}

As for measurement, there are three main influential factors. The first one is the standard operating procedures because substandard procedure may cause operational errors, reduce logistics efficiency, logistics interruption and damage or loss. The second important factor is logistics efficiency, which would decrease the fresh electricity suppliers cold chain logistics service quality, but also damage rate. The last is product damage rate. To improve the cold chain logistics service quality and efficiency is of great significance to win more customers and enhance the core competitiveness of business enterprises.

\section{Improvement Measures of Fresh Electricity Suppliers Cold Chain Logistics Service Quality}

According to the above mentioned influential factors of fresh electricity suppliers cold 
chain logistics service quality, it puts forward the following six improvement measures to optimize the process of fresh electricity suppliers cold chain logistics service, so as to improve service quality and online shopping experience of consumers.

\subsection{To Strengthen Staff Training and Improve Service Awareness}

The staff is the main body of logistics services, thus electricity suppliers should establish jointly with partners a customer-oriented service concept. It is necessary to intensity training for employees concerning logistics operation methods in every specific step and logistics service awareness. Meanwhile the logistics operation experience, stuff images and qualities should also be improved in the principle of serving for end customers. In addition to give appropriate care to the physical and psychological conditions of employees, it is required to make reasonable stuff shift arrangement so that employees can work with good spirits and high efficiency and accuracy. Lean human resource management is preferred to make the best use of men and materials. Only in these ways, can it be ensured that employees are full of passion for work, which would consequently improve the quality of logistics services.

\subsection{To Improve Logistics Equipment and Develop Cold Chain Technology}

To improve the logistics infrastructure is the basic premise of the improvement of electricity suppliers logistics services And fresh products have higher requirements for the logistics equipment and facilities so that the support of high cold chain technology is necessary. First, the standardized cold chain transport vehicle with cold storage function should be selected for the insurance of freshness of fresh products in transit, and the protection of fragile and perishable fresh products. Second, professional third party cold chain logistics enterprise and high quality logistics equipment can heighten the cold chain logistics service quality so as to create a wider group of customers for fresh electricity supplier enterprises. It would cost less than that taken by low tech facilities.

\subsection{To Improve the Material Supply and Meet Customer Demand}

To strengthen the management of fresh products suppliers and logistics enterprises, and ensure the qualities of fresh products and of packaging materials, the product packaging material should be selected as flexible according to the characteristics of fresh products. What is more, has because of the more and more personalized customer demands, electric business enterprises should make flexible and immediate responses to different customers needs make personalized packages, improve the online shopping experience of consumers and establish a good customer relationship through the construction of information platform.

\subsection{To Optimize the Distribution Route and Develop the Intelligent Logistics}

No matter fresh electricity suppliers choose the third party cold chain logistics or self- 
operated logistics, they are required to pay special attention to distribution route optimization, design a scientific and rational distribution route and be able to dispatch route and vehicle in time for emergencies. What is more, they must improve the timeliness of distribution, the vehicle on board rate and make goods arrive on time, thereby greatly reducing the cost of logistics, and achieve the purpose of timely delivery of goods to consumers. Fresh electricity suppliers should develop intelligent logistics in big data environment for the timely location of vehicle in operation and real-time information tracking, so that consumers can be kept informed of where are the goods. Moreover, the "last mile" problem is the key to online shopping consumer satisfaction, thus electricity suppliers are required to optimize the "last mile" distribution problem.

\subsection{To Carry out Lean Management and Reduce Logistics Cost}

Based on teamwork, lean supply chain and logistics management is to identify and eliminate the "waste", to achieve continuous improvement. "Waste" refers to those activities that do not add values from the customers' view. The employment of standard operation, 5S (organization and standardization of workplace), visual management and other basic lean tools can improve the logistics environment, make the operation process standardized, and lay a good foundation for the improvement of fresh cold chain logistics service quality. Internal lean logistics management of enterprises can be achieved by using Enterprise Resource Planning (ERP), Distribution Requirements Planning (DRP), Radio Frequency Identification (RFID), Transportation Management System (TMS) technology, etc. The communication and cooperation between the fresh electricity supplier enterprises and partners can be enhanced by using Electronic Data Interchange (EDI), Efficient Customer Response (ECR) and Quick Response (QR) technology and the like. Lean supply chain and logistics management can eliminate the

"waste" of the fresh cold chain logistics distribution, reduce the risk of product damage and improve the rate of goods on time, not only improve the quality of service, meet the needs of customers but also reduce the whole logistics cost [8].

\subsection{To Make Cold Chain Logistics Service Quality Management System and Strengthen Quality Control and Supervision}

Fresh electricity suppliers can develop cold chain logistics service quality management system. Through the quality planning, control and improvement to ensure the quality of logistics services. For instance, to develop process control plan, formulate relevant contingency plans, at the same time, electric business enterprise should perform quality control and improvement to the logistics service process continuously. To carry on the quality control of the service process that have improved through effective monitoring methods, in order to maintain the results of the improvement of the logistics process, and seek to continuous improvement method. To develop fresh electricity suppliers cold chain logistics standard operating procedures, so that all aspects of the operation can basis on a standard, and through the revision of documents and other methods to make the successful experience be institutionalized. 


\section{Conclusions}

This paper uses SIPOC model to draw the fresh electricity suppliers cold chain logistics service flow chart. On the basis of understanding the fresh electricity suppliers cold chain logistics service process, the factors affecting the quality of fresh electricity suppliers cold chain logistics service were analyzed from six aspects of personnel, machine, material, method, environment and measurement. This paper puts forward 6 measures to improve the fresh electricity suppliers cold chain logistics service quality: to strengthen staff training and improve service awareness; to improve logistics equipment and develop cold chain technology; to improve the material supply and meet customer demand; to optimize the distribution route and develop the intelligent logistics; to carry out lean management and reduce logistics cost; to make cold chain logistics service quality management system and strengthen quality control and supervision. It has important theoretical guiding role for the improvement of the fresh electricity suppliers cold chain logistics service quality.

The deficiency of this paper lies in that only the theoretical direction is given, the future should have more data collection, establish relevant models, research and formulate reasonable and systematic evaluation index system of fresh electricity suppliers cold chain logistics service quality.

\section{References}

[1] Shi, X.X. (2010) Application of 6 Sigma Management in Vegetable Cold Chain Logistics Enterprises in China. Market Modernization, 10, 34-36.

[2] He, X. (2010) Cold Chain Logistics Quality Control of Agricultural Products Based on HACCP. Farm Products Processing, 9, 69-70+73.

[3] Hou, J.L. and Li, L. (2015) Study on the Evaluation of Fresh Agricultural Products Cold Chain Logistics Service Quality of in B2C E-Commerce. Logistics Sci-Tech, 6, 132-135.

[4] Sui, L.H. and Tan, Q. (2015) Strategies and Suggestions on Improving Customer Satisfaction of Electric Business Logistics Distribution Enterprises. Logistics Technology, 9, 78-80.

[5] Wei, Z.C. (2015) Study on the Improvement Strategy of Electricity Supplier Logistics Service. Logistics Technology, 14, 66-68.

[6] Chen, H.L., Zhang, L.Y. and Zhang, X. (2015) Construction of Evaluation Model of Fresh Food Cold Chain Logistics Service Quality Based on FAHP. Logistics Technology, 13, $142-145+189$.

[7] Zhang, Y., Feng, Y.Q. and Kang, W.T. (2016) Logistics Service Quality Improvement of Electric Business Based on Six Sigma. Logistics Engineering and Management, 2, 25-27.

[8] Myerson, P. (2014) Lean Supply Chain and Logistics Management. POSTS\&TELECOM PRESS, Beijing. 